OPEN ACCESS

Edited by: Mohammad Abdulkader Akbarsha, National College, Tiruchirappalli, India

Reviewed by:

Jeetender Chugh,

Indian Institute of Science Education and Research, Pune, India

Shilpy Sharma,

Savitribai Phule Pune University, India

*Correspondence:

Lekha Divya

divyal@cukerala.ac.in

Specialty section: This article was submitted to

In Vitro Toxicology,

a section of the journal

Frontiers in Toxicology

Received: 24 February 2021

Accepted: 21 June 2021

Published: 19 July 2021

Citation:

Cc S, Arun D and Divya L (2021) Insect in vitro System for Toxicology

Studies - Current and Future Perspectives

Front. Toxicol. 3:671600 doi: 10.3389/ftox.2021.671600

\section{Insect in vitro System for Toxicology Studies - Current and Future Perspectives}

\author{
Sheeja Cc, Damodaran Arun and Lekha Divya* \\ Department of Zoology, Central University of Kerala, Kasaragod, India
}

In vitro cell culture practices are valuable techniques to understand the mechanisms behind vital in vivo biological processes. In vitro cells have helped us to attain a deeper understanding of functions and mechanisms conserved in the course of evolution. Toxicology studies are inevitable in drug discovery, pesticide development, and many other fields that directly interact with human beings. The proper involvement and regulatory steps that have been taken by animal ethical societies in different parts of the world resulted in the reduced in vivo use of mammals in toxicological studies. Nevertheless, experimental animals are being killed where no replacement is available. The use of mammals could be reduced by using the in vitro systems. Nowadays, invertebrate cell lines are also play important role in toxicology testing. This review analyzes the cause and consequence of insect in vitro models in toxicology studies.

Keywords: in vitro cell culture, toxicology, invertebrate, insect, toxicity screening

\section{INTRODUCTION}

Across centuries, research involving animals has contributed significantly to the progress of biomedical sciences (Festing and Wilkinson, 2007). However, use of animals in research experiments became a subject of controversy. The pain and sufferings experienced by animals had arisen the moral concerns which led to anti-vivisection movement. In 1824, the Royal Society for the Prevention of Cruelty to Animals ${ }^{1}$, one of the oldest animal welfare charities was formed. Later in 1876, an act for preventing cruelty to the animals was made in the UK (Balls, 1994; Doke and Dhawale, 2015). In India, parellel movements were initiated in the year 1960 (Doke and Dhawale, 2015). Then, the Animals Scientific Procedures Act (1986) came into existence and provided effective regulations enforced by law. During all these progressions, 3 Rs-replacement, reduction, and refinement of animals' use in research (Russell and Burch, 1959) have been proposed. The idea of "replacement" has led the researchers to search for alternatives. It mainly relied on replacing experimental mammals like rabbits, rats, and pigs with non-mammalian systems. Invertebrate models and micro-organisms were also introduced as a replacement to vertebrate models. Most of the intriguing biological questions could be addressed using lower group of organisms. In this review, we highlight the transformative potential of insect invertebrate system for in vitro toxicology studies.

\footnotetext{
${ }^{1}$ Royal Society for the Prevention of Cruelty to the Animals. Available online at: https://www.rspca.org.uk/.
} 


\section{RELEVANCE OF INVERTEBRATES IN RESEARCH}

Invertebrates have made significant contributions in biomedical research as most of their organs and their physiology are analogous to mammals (Svidersky and Plotnikova, 2002; Roch et al., 2014). Biomedical research using invertebrates has appeared in the scientific literature from the 1900's (WilsonSanders, 2011). They range from terrestrial invertebrates to freshwater and marine beings, including crustaceans and mollusks. During the last decade, articles published in PubMed revealed more than 250,000 entries on invertebrate models, which is comparatively higher than the previous year reports $(177,000)$. This indicates the efficiency of invertebrates as models in the biomedical research. Significant discoveries were made using invertebrates ranging from embryonic development to aging. For example, Caenorhabditis elegans, a nematode, possesses several advantages over the vertebrate model for biomedical research. For example, it has served as a model for the study on Parkinson's, Alzheimer's, Huntington's diseases, diabetes, cancer, immune disorders, and the development of therapeutic agents for these diseases (Faber et al., 1999; Link, 2001; Artal-Sanz et al., 2006; Nass et al., 2008; Pujol et al., 2008) having short generation time and inexpensive maintenance as its advantages (Nass et al., 2008). Other invertebrates have also been studied; for example, research on the squid giant axon provided the basis for the iconic nature of the electrical action potential in nerve transmission (Hodgkin and Huxley, 1952). In addition, invertebrates can be used for some screening purposes because their nervous systems are sufficiently complex and biochemically related to the human nervous system (https:// www.ncbi.nlm.nih.gov/books/NBK218269/) (National Research Council (US) and Institute of Medicine (US) Committee on the Use of Laboratory Animals in Biomedical and Behavioral Research et al., 1988). Rapid shifts in ethical regulations related to vertebrate experimentation point out how dynamic these issues have been. Nowadays, ethical concerns are being raised regarding the use of invertebrates too. Animal rights organizations like PETA (2017, 2018) and social activists like Geer (2015) have raised concerns about the ethical treatment of invertebrates (Drinkwater et al., 2019).

\section{INSECTS AS AN in vitro SYSTEM}

Insect cells have been successfully cultured in vitro for over 55 years. The first-ever invertebrate tissue culture started in 1915 when Richard Goldschmidt tried to examine silkworm testes' development in culture (Goldschmidt, 1915). Later in 1935, William Trager observed that silkworm testes in culture are suitable for virus replication studies (Trager, 1935). The first continuous invertebrate cell lines were developed by Grace (1962), from ovaries of the Australian Emperor gum moth, Antheraea eucalypti. Later, insect cells have emerged as a cost effective alternative host platform to the mammalian cell lines. A lesser manufacturing and maintenance cost than mammalian cells could be the reason behind such a rapid change.
TABLE 1 | Examples for well-established insect cell lines.

\begin{tabular}{|c|c|c|}
\hline Sl. no. & Insect in vitro system & Major use \\
\hline 1 & $\begin{array}{l}\text { Aedes albopictus } \\
\text { C6/36 }\end{array}$ & $\begin{array}{l}\text { Cadmium pathology (Braeckman } \\
\text { et al., 1999) }\end{array}$ \\
\hline 2 & $\begin{array}{l}\text { Spodoptera fugiperda } \\
\text { (Sf9) }\end{array}$ & $\begin{array}{l}\text { Cancer therapeutic strategies } \\
\text { (Jahanian-Najafabadi et al., 2012) } \\
\text { Fungal toxicity (Zhang et al., } \\
\text { 2017) }\end{array}$ \\
\hline 3 & $\begin{array}{l}\text { Spodoptera fugiperda } \\
\text { (Sf21) }\end{array}$ & $\begin{array}{l}\text { Recombinant protein expression } \\
\text { system }\end{array}$ \\
\hline 4 & $\begin{array}{l}\text { HighFive } \\
\text { (Trichoplusiani) }\end{array}$ & $\begin{array}{l}\text { Recombinant protein expression } \\
\text { system }\end{array}$ \\
\hline 5 & S2 (D. melanogaster) & Metal toxicity, pollutant toxicity \\
\hline
\end{tabular}

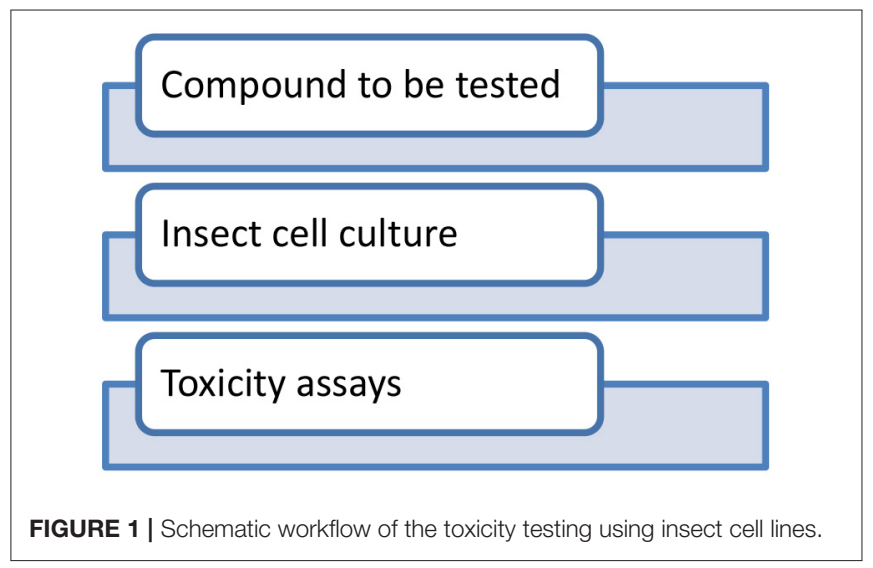

Most insect cells can be cultivated over a temperature range of $25-30^{\circ} \mathrm{C}$ and a $\mathrm{pH}$ of 6.2 . Unlike mammalian cells, insect cell lines utilize a phosphate buffering system (Lynn, 2002). The most established insect cell lines include S2 derived from D. melanogaster, Sf9 from Spodoptera frugiperda, and High Five from Trichoplusiani (Yee et al., 2018) (Table 1). Insect cell lines have advantages like non-essentiality of $\mathrm{CO}_{2}$, reduced biosafety requirements (BSL1), etc. (Airenne et al., 2013).

Among invertebrates, insects have been used as model organisms in biomedical research for a long time. The cornerstone insect widely used is Drosophila (Baker and Thummel, 2007). D. melanogaster is one of the well-studied organisms in the animal kingdom. Cytogenetic research has led to the complete mapping and sequencing of its chromosomes, leading to their continuous use in biological and biomedical investigations (Gilbert, 2008). For instance, research on the eye pigmentation of Drosophila led to the hypothesis that each gene controls a single enzyme-a concept that has proved fundamental to modern molecular biology (Ephrussi, 1942). Insects are well-proved as the best in vivo alternatives to mammals. The insect models, D. melanogaster, Galleria mellonella, Bombyx mori, and Manduca sexta provided similar results that can be obtained with mammalian systems (Fuchs and Mylonakis, 2006). 
Established protocols for testing chemicals in insects are already available (Perry et al., 1998). Compounds to be tested are injected to appropriate insect cell lines and subsequent toxicity assays are performed (Figure 1). Insecticidal effects of various compounds such as actions of biflavonesin on neuronal cells (Ren et al., 2021), Bt toxicity in the cabbage looper, Trichoplusiani (Wang et al., 2018), and CF-203 cell line (Li et al., 2018) were studied in detail, and it provided reliable results also. G. mellonella has a great future in the field of toxicology and as a model for antibacterial drug testing (Cutuli et al., 2019). The structural and functional similarities with mammalian immune system make insect hemocytes a suitable platform for conducting toxicology studies at immune system level (Browne et al., 2013). The homology in proteins such as insect malvolio and dSR-C1 with the macrophage protein NRAMP-1 (Kavanagh and Reeves, 2004) in mouse makes a strong case for using insects as an alternative. Recently, Sheeja et al. (2020) studied the cellular toxicity effects of molybdenum disulfide nanoparticles in the hemocytes culture of Oecophylla smaragdina. Likewise, environmental monitoring studies and screening of nanoparticles were conducted on many insect species such as D. melanogaster (Armstrong et al., 2013; Araj et al., 2015), Blaberus discoidalis (Zhou et al., 2020), B. mori (Pandiarajan and Krishnan, 2017; Mir et al., 2020), and Honey bees (Dubey et al., 2015). Recent advances in insect baculovirus expression vector (BEV) system indicate the growing industrial interest in commercial use of the BEV/insect cell culture system for the manufacture of biopharmaceuticals. Likewise, insect cell lines have a brighter future in the development of protein therapeutics (Yee et al., 2018). Recently, a COVID-19 candidate vaccine was formulated using insect cell lines in China ( $\mathrm{Li}$ et al., 2020). Along with advancements, there are a lot of limitations attached with insect cell line models. Though the

\section{REFERENCES}

Airenne, K. J., Hu, Y. C., Kost, T. A., Smith, R. H., Kotin, R. M., Ono, C., et al. (2013). Baculovirus: an insect-derived vector for diverse gene transfer applications. Mol. Ther. 21, 739-749. doi: 10.1038/mt.20 12.286

Animals Scientific Procedures Act (1986). Available online at: https://www. legislation.gov.uk/ukpga/1986/14/contents (accessed June 7, 2021).

Araj, S. A., Salem, N. M., Ghabeish, I. H., and Awwad, A. M. (2015). Toxicity of nanoparticles against Drosophila melanogaster (diptera: drosophilidae). J. Nanomater. 2015:9. doi: 10.1155/2015/758132

Armstrong, N., Ramamoorthy, M., Lyon, D., Jones, K., and Duttaroy, A. (2013). Mechanism of silver nanoparticles action on insect pigmentation reveals intervention of copper homeostasis. PLOS ONE 8:e53186. doi: 10.1371/journal.pone.0053186

Artal-Sanz, M., de Jong, L., and Tavernarakis, N. (2006). Caenorhabditis elegans: A versatile platform for drug discovery. Biotechnol. J. 1, 1405-1418. doi: $10.1002 /$ biot.200600176

Baker, K. D., and Thummel, C. S. (2007). Diabetic larvae and obese fliesemerging studies of metabolism in Drosophila. Cell Metab. 6, 257-266. doi: 10.1016/j.cmet.2007.09.002

Balls, M. (1994). Replacement of animal procedures: alternatives in research, education and testing. Lab. Anim. 28, 193-211. doi: $10.1258 / 002367794780681714$ insect cell system becomes famous for in vitro approaches, there are evident limitations. $\mathrm{N}$ - glycosylation in insect cell lines is not alike as seen in mammalian systems. Many insect species lack capabilities to elongate the core pentasaccharide Man3GlcNac2. It will be difficult if the recombinant protein require glycans for its maintenance. Likewise, "the cell density effect," a sudden decline in the productivity and cell concentration is prominent in insect cell lines. Insect cell lines should be modified in a way that it meets all the requirements that a mammalian cell lines generally performs. Generating adequately modified insect cell lines may replace the existing mammalian cell lines.

\section{CONCLUSION}

The invertebrate models especially insects are established as successful in vivo models for toxicological studies. That could greatly replace many mammalian systems too. Insect in vitro models started gaining attention considering its less maintenance time and cost-effectiveness. Many insect cell lines offer several advantages over mammalian cell lines. Detailed studies are necessary to further reveal the great potential of invertebrate, especially insect in vitro system.

\section{AUTHOR CONTRIBUTIONS}

SC, DA, and LD: wrote the manuscript. All authors contributed to the article and approved the submitted version.

\section{ACKNOWLEDGMENTS}

We would like to acknowledge Central University of Kerala and the Department of Science and Technology (DST) for the INSPIRE Fellowship to SC.
Braeckman, B., Brys, K., Rzeznik, U., and Raes, H. (1999). Cadmium pathology in an insect cell line: ultrastructural and biochemical effects. Tissue Cell 31, 45-53. doi: 10.1054/tice.1998.0019

Browne, N., Heelan, M., and Kavanagh, K. (2013). An analysis of the structural and functional similarities of insect hemocytes and mammalian phagocytes. Virulence 7, 597-603. doi: 10.4161/viru.25906

Cutuli, M. A., Petronio, G. P., Vergalito, F., Magnifico, I., Pietrangelo, L., Venditti, N., et al. (2019). Galleria mellonella as a consolidated in vivo model hosts: New developments in antibacterial strategies and novel drug testing. Virulence. 10, 527-541. doi: 10.1080/21505594.2019.1621649

Doke, S. K., and Dhawale, S. C. (2015). Alternatives to animal testing: A review. Saudi Pharm. J. 23, 223-229. doi: 10.1016/j.jsps.2013.11.002

Drinkwater, E., Robinson, E. J. H., and Hart, A. G. (2019). Keeping invertebrate research ethical in a landscape of shifting public opinion. Methods Ecol. Evol. 10, 1265-1273. doi: 10.1111/2041-210X.13208

Dubey, P., Matai, I., Kumar, S. U., Sachdev, A., Bhushan, B., and Gopinath, P. (2015). Perturbation of cellular mechanistic system by silver nanoparticle toxicity: Cytotoxic, genotoxic and epigenetic potentials. Adv. Colloid Interface Sci. 221, 4-21. doi: 10.1016/j.cis.2015.02.007

Ephrussi, B. (1942). Analysis of eye color differentiation in Drosophila, Cold. Spring Harbor Symp. Quant. Bio. 10, 40-48.

Faber, P. W., Alter, J. R., Macdonald, M. E., and Hart, A. C. (1999). Polyglutaminemediated dysfunction and apoptotic death of a Caenorhabditis elegans sensory neuron. Proc. Natl. Acad. Sci. U. S. A. 96, 179-184. doi: 10.1073/pnas.96.1.179 
Festing, S., and Wilkinson, R. (2007). The ethics of animal research. Talking Point on the use of animals in scientific research. EMBO Rep. 8, 526-530. doi: 10.1038/sj.embor.740 0993

Fuchs, B. B., and Mylonakis, E. (2006). Using non-mammalian hosts to study fungal virulence and host defense. Curr. Opin. Microbiol. 9, 346-351. doi: 10.1016/j.mib.2006.0 6.004

Geer, A. (2015). Do You Support Using Insects as Military Weapons? Available online at: https://www.care2.com/causes/do-you-support-using-insects-asmilitary-weapons.html (accessed June 02, 2021).

Gilbert, L. I. (2008). Drosophila is an inclusive model for human diseases, growth and development. Mol. Cell. Endocrinol. 293, 25-31. doi: $10.1016 /$ j.mce.2008.02.009

Goldschmidt, R. (1915). Some experiments on spermatogenesis in vitro. Proc. Natl. Acad. Sci. U.S.A. 1, 220-222.

Grace, T. D. C. (1962). Establishment of four strains of cells from insect tissue grown in vitro. Nature 195, 788-789.

Hodgkin, A. L., and Huxley, A. F. (1952). A quantitative description of membrane current and its application to conduction and excitation in nerve. J. Physiol. 117, 500-544. doi: 10.1113/jphysiol.1952.sp0 04764

Jahanian-Najafabadi, A., Bouzari, S., Oloomi, M., Roudkenar, M. H., and Shokrgozar, M. A. (2012). Assessment of selective toxicity of insect cell expressed recombinant A1-GMCSF protein toward GMCSF receptor bearing tumor cells. Res Pharm Sci. 7, 133-140.

Kavanagh, K., and Reeves, E. P. (2004). Exploiting the potential of insects for in vivo pathogenicity testing of microbial pathogens. FEMS Microbiol. Rev. 28, 101-112. doi: 10.1016/j.femsre.2003.09.002

Li, T., Zheng, Q., Yu, H., Wu, D., Xue, W., Xiong, H., et al. (2020). SARS-CoV-2 spike produced in insect cells elicits high neutralization titres in non-human primates. Emerg. Microbes Infect. 9, 2076-2090. doi: $10.1080 / 22221751.2020 .1821583$

Li, X., Zhao, F., Qiu, X., Ren, X., Mo, X., Ding, X., et al. (2018). The full-length CrylAc protoxin without proteolytic activation exhibits toxicity against insect cell line CF-203. J. Invertebr. Pathol. 152, 25-29. doi: 10.1016/j.jip.2018.01.004

Link, C. D. (2001). Transgenic invertebrate models of age-associated neurodegenerative diseases. Mech. Ageing Dev. 122, 1639-1649. doi: 10.1016/S0047-6374(01)00291-3

Lynn, D. E. (2002). Methods for maintaining insect cell cultures. J. Insect Sci. 2:9. doi: $10.1093 /$ iis/2.1.9

Mir, A. H., Qamar, A., Qadir, I., Naqvi, A. H., and Begum, R. (2020). Accumulation and trafficking of zinc oxide nanoparticles in an invertebrate model, Bombyx mori, with insights on their effects on immuno-competent cells. Sci Rep. 10:1617. doi: 10.1038/s41598-020-58526-1

Nass, R., Merchant, K. M., and Ryan, T. (2008). Caenorhabditis elegans in Parkinson's disease drug discovery: Addressing an unmet medical need. Mol. Interv. 8:284. doi: 10.1124/mi.8.6.6

National Research Council (US) and Institute of Medicine (US) Committee on the Use of Laboratory Animals in Biomedical and Behavioral Research. Use of Laboratory Animals in Biomedical and Behavioral Research. Washington DC: National Academies Press (US) (1988). Alternative Methods in Biomedical and Behavioral Research. Available online at: https://www.ncbi.nlm.nih.gov/books/ NBK218269/ (accessed June 4, 2021).

Pandiarajan, J., and Krishnan, M. (2017). Properties, synthesis and toxicity of silver nanoparticles. Environ. Chem. Lett. 15, 387-397. doi: $10.1007 / \mathrm{s} 10311-017-0624-4$
Perry, A. S., Yamamoto, I., Ishaaya, I., and Perry, R. (1998). "Methods of testing chemicals on insects," in Insecticides in Agriculture and Environment. Applied Agriculture (Berlin: Springer). doi: 10.1007/978-3-662-03656-3_5

PETA (2017). Drop the Flyswatter: Insects are Conscious. Available online at: https://prime.peta.org/2017/05/drop-flyswatter-insects-conscious (accessed May 2, 2019).

PETA (2018). Real Talk: Do Bugs Feel Pain? Available online at: https://www.peta2. com/news/do-bugs-feel-pain/ (accessed April 12, 2019).

Pujol, N., Cypowyj, S., Ziegler, K., Millet, A., Astrain, A., Goncharov, A., et al. (2008). Distinct innate immune responses to infection and wounding in the C. elegans Epidermis. Curr. Biol. 18, 481-489. doi: 10.1016/j.cub.2008.0 2.079

Ren, Y., Li, Q., Lu, L., Jin, H., Tao, K., and Hou, T. (2021). Toxicity and physiological actions of biflavones on potassium current in insect neuronal cells. Pesticide Biochem. Physiol. 171:104735. doi: 10.1016/j.pestbp.2020.104735

Roch, G. J., Tello, J. A., and Sherwood, N. M. (2014). At the transition from invertebrates to vertebrates, a novel GnRH-like peptide emerges in amphioxus. Mol. Biol. Evol. 31, 765-778. doi: 10.1093/molbev/mst269

Russell, W. M. S., and Burch, R. L. (1959). The Principles of Humane Experimental Technique, London: Methuen.

Sheeja, C. C., Anusri, A., Levna, C., Aneesh, P. M., and Lekha, D. (2020). MoS2 nanoparticles induce behavioral alteration and oxidative stress mediated cellular toxicity in the social insect Oecophylla smaragdina (Asian weaver ant). J. Hazardous Mater. 385:121624. doi: 10.1016/j.jhazmat.2019.121624

Svidersky, V. L., and Plotnikova, S. I. (2002). Insects and vertebrates: analogous structures in higher integrative centers of the brain. J. Evolut. Biochem. Physiol. 38, 627-639. doi: 10.1023/A:1022073218825

Trager, W. (1935). Cultivation of the virus of grasserie in silkworm tissue cultures. J. Exp. Med. 61, 501-513.

Wang, S., Kain, W., and Wang, P. (2018). Bacillus thuringiensis Cry1A toxins exert toxicity by multiple pathways in insects. Insect Biochem. Mol. Biol. 102, 59-66. doi: 10.1016/j.ibmb.2018.09.013

Wilson-Sanders, S. E. (2011). Invertebrate models for biomedical research, testing, and education. ILAR J. 52, 126-152. doi: 10.1093/ilar.52.2.126

Yee, C. M., Zak, A. J., Hill, B. D., and Wen, F. (2018). The coming age of insect cells for manufacturing and development of protein therapeutics. Ind. Eng. Chem. Res. 57, 10061-10070. doi: 10.1021/acs.iecr.8b00985

Zhang, H., Zhang, L., Diao, X., Li, N., and Liu, C. (2017). Toxicity of the mycotoxin fumonisin $B_{1}$ on the insect Sf9 cell line. Toxicon. 129, 20-27. doi: 10.1016/j.toxicon.2017.01.018

Zhou, Y., Chen, Y., Rocha, A., Sanchez, C. J., and Liang, H. (2020). Assessment of toxicity of nanoparticles using insects as biological models. Methods Mol. Biol. 2118, 269-279. doi: 10.1007/978-1-0716-0319-2_20

Conflict of Interest: The authors declare that the research was conducted in the absence of any commercial or financial relationships that could be construed as a potential conflict of interest.

The handling editor declared a past co-authorship with several of the authors DA and LD.

Copyright $\odot 2021$ Cc, Arun and Divya. This is an open-access article distributed under the terms of the Creative Commons Attribution License (CC BY). The use, distribution or reproduction in other forums is permitted, provided the original author(s) and the copyright owner(s) are credited and that the original publication in this journal is cited, in accordance with accepted academic practice. No use, distribution or reproduction is permitted which does not comply with these terms. 